\section{Introducing the Chinese Commons}

\section{Andrea E. Pia}

'[China's] environment can no longer keep pace. Acid rain is falling on one third of China's territory, half of the water in our seven largest rivers is completely useless, while one fourth of our citizens do not have access to clean drinking water. One third of the urban population is breathing polluted air, and less than twenty percent of the rubbish in cities is treated and processed in an environmentally sustainable manner. Finally, five of the ten most polluted cities worldwide are in China.' This is an interview that Pan Yue-a former vice-minister of the Chinese Ministry of Environmental Protection (huanjing baohubu)-gave in 2005. During his time in office, Pan Yue introduced many radical ideas about possible solutions for China's environmental issues, including a proposal for more democratic control over environmental policy-making. Interestingly, the Chinese authorities have now embraced some of Pan's ideas as part of a national policy effort that goes under the name of 'Ecological Civilisation' (shengtai wenming). Ecological Civilisation stems from the recognition that any possibility for the reversal of the country's ecological decline must come from an overall rethinking of its development strategies. Practically, the Central Committee of the Chinese Communist Party has, thus far, supported the establishment of an ecological compensation mechanism, supplementing GDP measurements with quality indicators that take into account environmental issues.

Pundits and government spokespersons are telling environmentalists worldwide to rejoice for what has been hailed as a veritable change of paradigm in China's model of economic growth, from the plundering of natural resources to the rejuvenation of the country's environment. And yet, despite the growing number of official statements and guidelines released by the Central Committee since 2013, there are those who fear that such suggestions will not go far enough in addressing the global magnitude and consequences of China's ecological decline.

If anything, the situation in China has gotten even worse since Pan's interview. According to the available data, almost twenty percent of China's agricultural land is now contaminated, while sixty percent of China's underground water supplies are said to be polluted. Drinking water in most of the country's rural areas is unfit for human consumption because of pollution from fertilisers, pesticides, and industrial activity. Meanwhile worsening air quality has resulted in China taking the top spot in the world rankings for deadliest outdoor air pollution. Crucially, many of China's current environmental issues seem to originate from the state's apparent inability to manage, on its own terms, the manifold dimensions of the country's ecological crisis. Desertification is expanding on an average of one thousand and five hundred square miles per year, in part because of ill-conceived and counterproductive governmental attempts at stopping soil erosion through reforestation. Sustainable grassland management in Tibet deteriorates as China implements energy substitution policies intended to alleviate the country's dependence on coal. Finally, while the industry of waste processing is now making a substantial contribution to China's 'green growth', it is the country's poorest, and those across its borders, who bear the burden of the industry's pollution.

How should we interpret the current crisis? How are Chinese citizens meant to organise themselves so that they might preserve and restore the environment they rely on and commonly share? This issue of Made in China deals with the rupture between unilaterally advocated projects for national and environmental renewal, and those 
popular voices, practices, and ideas which are usually left unregistered at the margins of the environmental debate. We look into the contemporary shapes and dynamics of Chinese citizens' engagements with the rejuvenation of their environment, and interrogate their potential for articulating workable alternatives. We give a name to our collective ethnographic intrusions into this topic: the 'commons'. While this is a word that has recently received a lot of attentionespecially thanks to the work of Elinor Ostrom-here we wish to extend its meaning. Ostrom has been rightly awarded a Nobel Prize for empirically demonstrating that ordinary people have the capacity to sustainably manage the environment without state supervision or the creation of market forces. They do so by managing the environment in common, that is by equipping themselves with collegially crafted rules that enable them to modulate their competing needs with a view to fostering their community's longterm flourishing and accommodating the fluctuating availability of natural resources.

We build on Ostrom's formulation, but we are wary of the ways in which her work has recently been co-opted by several international institutions and government agencies dancing to the tune of neoliberal politics. Since Garrett Hardin's Tragedy of the Commons, the concept of the commons has, in fact, served as a Trojan horse to smuggle a host of technocratic instruments into environmental politics. Instruments contrary to what the notion of the commons was originally meant to achieve: wealth concentration. Institutionalising the idea of the commons has meant the rekindling of top-down political proposals to achieve environmental sustainability that is also growth compatible through moreand allegedly better designed-market mechanisms and incentives. With this issue we wish to reclaim the term, the commons, in order to serve a different agenda.

To achieve this, we expand Ostrom definitions of rules and the environment. With 'environment' we don't simply refer to a collection of disposable matter, but to the assemblage of infrastructure, institutions, and life forms-the mutual relationships of which we humans have progressively reimagined and folded back into nature to pursue the best interest of our species. Stretching the meaning of the word 'environment' this way allows us to scrap the untenable nature/culture dichotomy underpinning Ostrom's approach, thus precluding the idea that sustainability can be achieved without the corresponding changes in our capitalist order. The idea of rules is subjected to a similar process of re-theorisation. Rules, and the codification of behaviour they entail, are only rarely the way Ostrom sees them: the product of an effort 'to achieve order and predictability' in a community of resource users. Rather, our case studies will show how processes of rule creation lead to alternative methods of action that may actually subvert the established order of resource extraction and consumption, fighting against the predictability of incessant capitalist expansion and commoditisation of nature.

What do we gain from looking for this expanded commons in China? What types of aspirations, creativity, and commitments do the commons give rise to in this country? Our ethnographic explorations of the Chinese commons will look into existing projects that seek to make the environment a common resource. We investigate the latent potential of everyday forms of resistance, refusal, and dissent for redrawing the frontiers of resource commodification in the increasingly degrading ecology of contemporary China. 